Disponible en: http://www.revistasice.com/cmsrevistasICE/pdfs/

- El EMPLEO MEDIOAMBIENTAL EN ESPAÑA

http://www.ecoempleo.com/downloads/empleoambiental/spain/1/0 Iintro.pdf

- SECTORES ECONOMICOS EMERGENTES EN ANDALUCIA

http ://www ,cea .es/portalcea/pymes/creacion_empresa/sectores. aspx

- La industria medioambıental española mueve 10.000 millones cada año, según el

ICEXhttp://www.consumer_es/web/es/medio_amblente/2003/09/29/66126.phpMinister io de Ambiente, Vivienda y Desarrollo

Territorialhttp://www. mi nambiente gov. co/contenido/contenido.aspx?catID =15 1\& conID $=293$

\title{
LA ADMINISTRACIÓN COMO ELEMENTO FUNDAMENTAL DEL DESARROLLO HUMANO
}

\section{Nancy Paola Ramírez Becerra}

Grupo Construyendo Comunidad Educativa

Desde tiempos muy remotos el hombre siempre se ha preocupado por estar a la van guardia y ser pionero en todas las actividades que realiza. En un momento antiguo podemos darnos cuenta que las ideas eran mas avanzadas que el hombre, pero ahora es el hombre quien vive mas que las ideas. "El pensamiento Administrativo esta condicionado por esa realidad y generación sobre el acto administrativo se produce en lapsos cada vez menores." ${ }^{\text {"1 }}$

No solo esto se ve reflejado en estos tiempos sino, cuando aun las antiguas civilizaciones americanas no habían sido gobernadas por las colonias españolas. Tanto lo Mayas como los Aztecas y los Incas tuvieron que verse envueltos en un proceso de planeación, dirección y control de sus tribus. Ellos eran excelentes administradores puesto que a diario estaban en condiciones de poner en práctica sus conocimientos de agricultura, la pesca, la artesanía y muchas actividades que requerían de mucha organización para poder sobrevivir.

En este instante es el mejor ejemplo que tenemos de Administración como ciencia avanzada en la vida del hombre primitivo. Es valido aclarar que en estas antiguas civilizaciones el que tenía la voz de mando era el jefe de la tribu. El era quien tomaba las decisiones. Prácticamente lo podríamos comparar con el gerente de hoy. Un ser dinámico, con mucha astucia, capaz de liderar procesos

'HERNANDEZ YRODRIGUEZ, Sergio. Fundamentos de Administración. Pág. 51 
de desarrollo evolutivo para su grupo y poder lograr una buena organización de las tareas asignadas a cada quien. Es de esta manera como empezamos a hablar de "primeras empresas". Estas como cualquier otra en la actualidad tenían fines diferentes: la caza, la pesca, la fabricación de herramientas etc. También había repartición de actividades pues mientras los hombres se dedicaban a estas tareas, las mujeres se encargaban de labores domesticas como recoger frutos, tejer e hilar. Tanto el hombre como la mujer primitiva. Se ligaron a muchos acontecimientos que posteriormente darían pasos agigantados para su evolución.

La escritura como el lenguaje con el paso del tiempo ha servido de puente para la elaboración de investigaciones tanto puras como aplicadas en sus estilos de vidas tan rudimentarios.

Cuando aun no se tiene un concepto de Administración bien definido, el hombre ha tratado de aplicar sus conocimientos y buscar la manera de darlos a conocer a las personas que lo rodean. Así como lo hemos visto en grandes documentales el gran Egipto es considerado como la empresa más antigua del mundo. Sus características y perfiles con procesos administrativos fueron:

Su poder era jerarquizado y sus terrenos eran divididos por el faraón donde existía un gobernador, eso sin olvidar que la máxima autoridad era el.

$\square$ Se lograban recaudar impuestos, para el control estricto de las actividades industriales realizadas por sus miembros.

$\square$ Se tenia un objetivo principal: el país debería ser el mas grande fuerte en cuanto economía se trataba. "Conviene agregar que también se puede identificar en Egipto antiguas formas de Administración Industrial que constituyeron antecedentes en las funciones y principios administrativos. ${ }^{\text {"2 }}$

Al igual que Egipto, China también se caracterizo por tener un sistema organizacional jerarquizado. El poder era asumido por el rey, y a la vez este daba ciertos privilegios a los príncipes que gobernaban pequeñas provincias sin perder el respeto a la máxima autoridad. Su legado más importante fue la "Constitución" de chow, donde existen ocho factores para el desarrollo de una buena organización: organización, funciones, relaciones, procedimientos, ceremonias, control, sanciones y registros. Tales factores han sido de gran ayuda para el desarrollo del pensamiento administrativo y el quehacer de hoy.

Es muy fácil darnos cuenta de que el hombre en algunas circunstancias carece de intelectualismo y de que en varias oportunidades quiera trabajar solo, pero

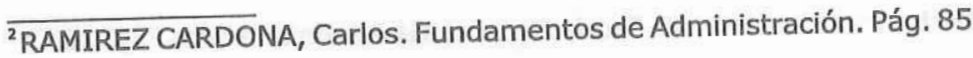


así es imposible que logre desarrollar los objetivos trazados sin ayuda de terceros.

Es importante señalar de una manera muy especifica un comentario muy original de esta idea desarrollada: "En el trascurso de la historia de la humanidad siempre existió alguna forma rudimentaria de administrar las organizaciones desde las simples hasta las mas complejas." ${ }^{\prime 3}$

Particularmente me gusta mucho ese punto de vista de Chiavenato, creo que es muy acertada su apreciación de lo que para el significa la Administración. Los grandes gobernantes del mundo han tenido una manera muy peculiar de liderar las organizaciones que tienen en su poder. De una u otra forma lo han hecho con los conocimientos que tienen en su poder o con la ayudad de súbditos, pero han dejado una reseña de lo importante de cada actividad que realizaron.

Pero en realidad ies verdaderamente importante saber de administración en algún punto de Muestras vidas? De manera Muy personal creo que si. Este es un proceso de vital importancia en el desarrollo de la vida de una persona porque contribuye al fortalecimiento interior de sus conocimientos y expectativas. Vale aclarar que no siempre nuestra cultura también necesito de administración, además se puede explicar que la organización eclesiástica de la Iglesia también influyo mucho y profundamente en el pensamiento administrativo.

Después de haber desarrollado algunas apreciaciones del pensamiento administrativo en la antigüedad quisiera hacer una breve exaltación de lo que es administración hoy en día. Se ha centralizado la administración como una ciencia aplicada en cada organización y que de una u otra manera las antiguas teorias le dieron un paso muy importante en la vida del ser humano. Gracias a muchos adelantos de la ciencia la administración ha tomado una gran importancia en la toma de decisiones de la organización como tal.

En la actualidad aun muchos paises toman como guía las bases de las teorías clásicas y científica. Es valido aclarar que estamos en la era de las comunicaciones en la cual el conocimiento de los trabajadores constituye los recursos fundamentales de la sociedad.

En este escrito quise citar algunas autores y sus pensamientos que han surgido con el paso de los años y que han hecho que la administración sea considerada como parte del desarrollo humano. Cuando interpreto alguna de las ideologías de estos escritores veo como cada uno tiene una percepción diferente de lo que

${ }^{3}$ CHIAVENATO, Idaberto. Introducción a teoría General a la Administración. Pág. 29 
para ellos es la administración en todos los campos investigativos.

En conclusión, dando a conocer algunas de las expectativas que tengo hacia lo que la administración significa en mi vida personal. En verdad hace parte fundamental en la vida del ser humano y de las herramientas suficientes para la toma de decisiones en el proyecto de vida de cada uno. Es importante resaltar que el proceso de administración es una base fundamental para investigar y de esta manara estaríamos generando conocimiento pues en estos tiempos el que lo posea tiene fuerza de poder. De esta manera es elemental conocer que la administración dejo de ser algo innecesario para convertirse en: "el proceso de planear, organizar, dirigir y controlar los esfuerzos de los miembros de la organización y de aplicar los demás recursos en ellas para alcanzar las metas establecidas. ${ }^{\prime 4}$

\title{
BIBLIOGRAFÍA
}

- Biblioteca de Consulta Microsoft Encarta 2005. 1993-2004 Microsoft Corporation. Reservado todos los derechos.

- CARDONA RAMIREZ, Carlos. Fundamentos de Administración. Ecoe Ediciones, 1999

- CHIAVENATO, Idalberto. Introducción a la Teoría de la Administración. Mc Graw Hill. 2001.

- HERNANDEZ Y RODRIGUEZ, Sergio. Fundamentos de Administración. Editorial Interamericana. STONER, James. FREEMAN, Edward. GILBERT, Daniel Jr. Administración. Prentice Hall, 1996

- SCHERMERHORN, Jhon. Administración. Limusa Wiley, 2003.

\section{REVALORIZACION DE RESIDUOS DE LA INDUSTRIA ALIMENTARIA DE LA REGIÓN BOYACENSE PARA LA OBTENCIÓN DE BIOPROTEINA}

\author{
Reyes J, Carreño $\mathbb{N}$, Páez $\mathbb{P}_{\text {, Chaparro J. }}$
} Grupo de investigación en Química Ambiental

\section{RESUMEN}

Se realizó la revalorización de los residuos de tres industrias alimentarias de la región boyacense mediante la transformación en bioproteína de levadura

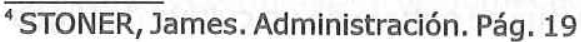

